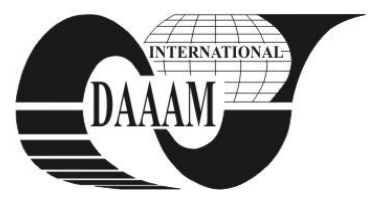

Annals of DAAAM for 2011 \& Proceedings of the 22nd International DAAAM Symposium, Volume 22, No. 1, ISSN 1726-9679 ISBN 978-3-901509-83-4, Editor B. Katalinic, Published by DAAAM International, Vienna, Austria, EU, 2011 Make Harmony between Technology and Nature, and Your Mind will Fly Free as a Bird Annals \& Proceedings of DAAAM International 2011

\title{
COMPUTER SIMULATION OF MEASUREMENT PROCESS AND SYSTEMS
}

\author{
VOLF, L[udek] \& BERANEK, L[ibor]
}

\begin{abstract}
Article deals with usage of tools from the area of computer simulation of the measurement process and systems. Simulation model has to verify influence of the measurement process and systems set-up of the welding line. Simulation model is based on the current state of the production system and deals with suggestions for its optimization.

Key words: manufacturing process, manufacturing system, simulation, productivity, welding line
\end{abstract}

\section{SIMULATION OF MEASUREMENT PROCESS AND SYSTEMS}

Simulation is a research method that consists in the replacement of the analysis of simulation model with which we perform experiments to obtain information on the original analysed system.

Simulation, as one of the digital factory tools, a tool for design and optimization of production systems in industry, became in recent years crucial because of intense development of the power of the computer technology and mainly due to more intense competition in a globalized world. Simulation is one of the means to reduce costs, increase profits, and generally to increase competitiveness. Simulation methods are used to find applications in examining the impact of the proposed innovation, the search and verification of appropriate rules of procedure, satisfability of production plans, increase production throughput with minimum inventory levels and operating costs, the search of modes satisfied the economic and environmental constraints, planning, reorganization, shutdowns, maintenance, replacement of plant and the use of labor and finding of other bottlenecks (Warner, 2009).

In examining the above problems we use the main advantages of simulation models, which are the possibilities of alternative solutions or proposals for action before the actual implementation in the manufacturing process, respectively system is made.

\section{PROPOSAL FOR A NEW CONCEPT OF WELDING LINES}

\subsection{Current state}

Company, for which we worked out simulation models of the welding lines, including measuring devices to monitor the dimensional tolerances of TIG welding the side, engaged in the manufacture of construction products and their accessories. Production is in continuous mode. Currently, one of the production halls of the race includes a welding workplace with technological structure. Part of the workplace is organized as a solutions in four welding lines, divided by subject production as follows:

$1 \mathrm{st}$ line $=$ weldments to $50 \mathrm{~kg}$ ( 5 work places $)$

2nd line $=$ welded line with the prevailing longitudinal dimension in the

proportion $1: 2,5$ to $200 \mathrm{~kg}$ ( 4 work places) 3rd line $=$ welded box shape with a balanced ratio to $200 \mathrm{~kg}$ (4 work places)

4 th line $=$ welded solid shape over $200 \mathrm{~kg}$ ( 3 work places)

All four lines are supplied independently of each other and their production processes are not linked or tied. Inter handling of the material is ensured by a combination of manual and electric trolley and workshop cranes for the establishment of semi-finished products into the workspace. For each side we have a unit times, batch times (set-up times), machine reliability and mean time to remove any faults. Also, times required for dimensional control are known.

The fundamental problem in this concept of the production system is primarily in process transport and uncoordinated dimensional control. Between workplaces semi-product spend 2 to 240 minutes for non-production activities, such as waiting for a crate, transport trolley, the release of a crane, redundant and arbitrary manipulation. Workplace length measurement is not filled permanent operator does not have standardized equipment and measuring devices.

\subsection{Intention to improve}

In order to minimize non-productive times or completely eliminated it, the formation of technical preparation suggested several types of technical and organizational structure of the existing welding lines. One suggestion was to eliminate transoperational one-piece buffer for replacement of the current inter-operational transport trolley by belt conveyor. On this conveyor is to be set up in semi-product and between the workplace to move within a specified interval (beat production) in order to avoid any unproductive time during today unorganize transportation.

\subsection{Simulation model}

Given the difficult concept of conceivability new interoperable solutions handling conveyor and especially in particular quantification of the impact of this measure on the overall productivity of the welding line, it was decided to create a simulation model of the existing production system and model of the new arrangement (Bangsow 2010). Further examination should be focused primarily on the change in lead times of production, the overall productivity of welding lines and capacity of workstations [9]. Similarly, measures of workplace inspections should be simulated with a fixed assignment operator, and defined sequence of activities.

To create a simulation model, we used the program "PlantSimulation" overarching package of programs Tecnomatix Siemens Product Lifecycle Management Software (CZ) Ltd.

\subsubsection{Simulation model of 2 nd line - origin state}

Line No. 2, Fig. 1, welded to the longitudinal dimension in the prevailing rate of $1: 2,5$ to $200 \mathrm{~kg}$, consists of four workplaces, among which are three trans-operational one-piece buffers. This line is for the purpose of the demonstration seems best.

Workplaces models (SP) are filled with data on the 
manufacturing process. These include unit and batch times, machine reliability and mean time to eliminate defects. PlaceBuffers characterize swap for one product and nonproductive idle times resulting from uncoordinated randomprocess and shipments are filled with loss times.

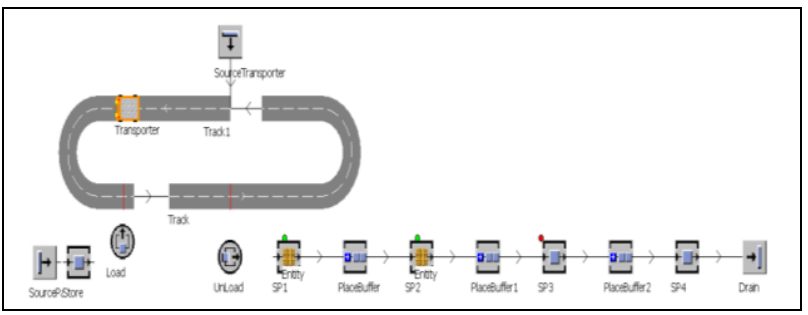

Fig. 1. Simulation model of 2nd line

In Fig. 2 we see a graphical representation of individual consumption of production time each workplace on 2nd line. For example, at least busy workplace SP1 line works only 5\% of shift time and $92 \%$ of shift time is used unproductively - is waiting for the full product from the previous work (warehouse).

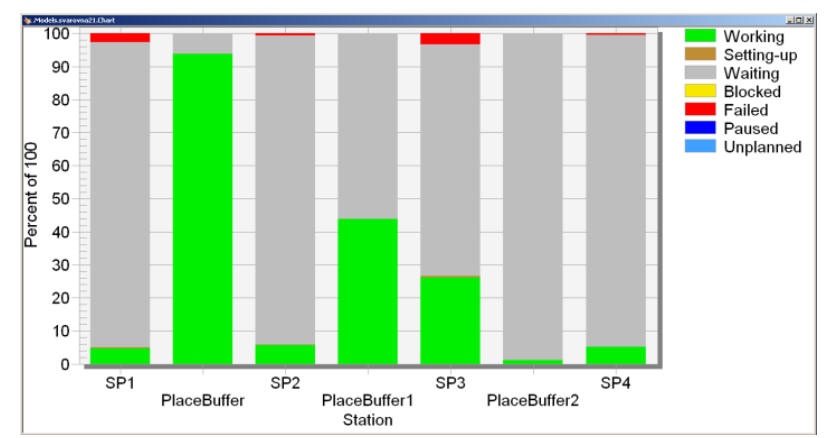

Fig. 2. Use of production (shift) time on 2nd line

\subsubsection{Simulation model - new state}

In the new design layout of the welding line have been replaced all the trans-operational buffers by belt conveyor, while the proposed unification of several offices and supplies for all lines, as shown in Fig. 3.

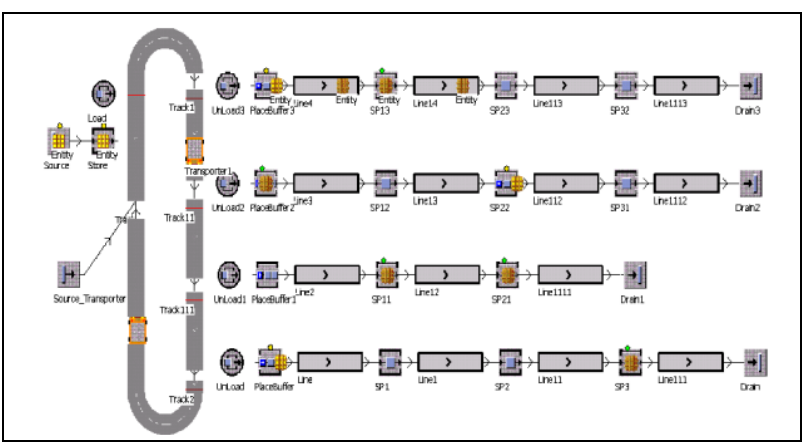

Fig. 3. Proposal for new layout

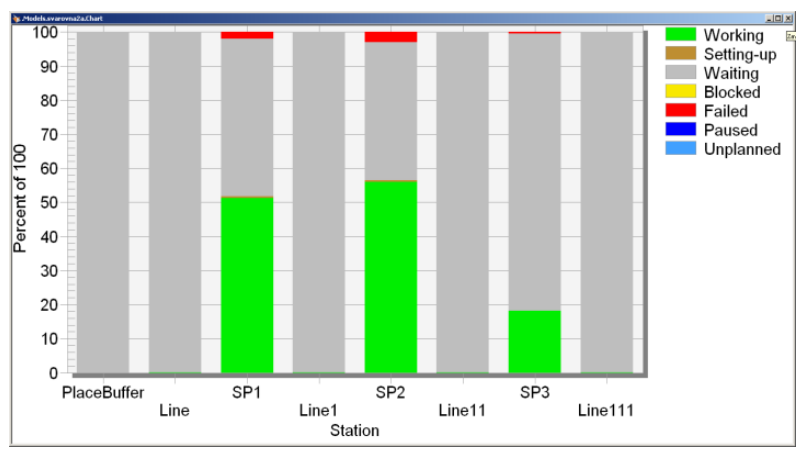

Fig. 4. Use of production (shift) time on 2nd line - new layout
In Fig. 4 we see a graphical representation of individual consumption of production time each workplace on 2 nd line after the introduction of the new layout. Time consumption structure has changed radically, as the above-mentioned workplace SP1 lines now works $51 \%$ of productive work of shift time. A similar jump in the increase of usability for the workplace became SP2 and other workplaces of other lines. To further improve the use shift time is necessary to focus on the process of supplying material and capacity balance all of lines. A fundamental change occurred in the overall productivity of the lines, see Table 1.

\begin{tabular}{|c|c|c|c|c|}
\hline \multirow{2}{*}{$\begin{array}{c}\text { welding } \\
\text { line } \\
\text { nr. }\end{array}$} & \multicolumn{2}{|c|}{$\begin{array}{c}\text { productivity } \\
\text { [pc / 24h] }\end{array}$} & \multicolumn{2}{c|}{$\begin{array}{c}\text { lead time for } 1 \mathrm{ks} \\
\text { [h:min] }\end{array}$} \\
\cline { 2 - 5 } & \multicolumn{2}{|c|}{ layout } & \multicolumn{2}{|c|}{ layout } \\
\cline { 2 - 5 } & origin & new & origin & new \\
\hline 1 & 4 & 28 & $8: 15$ & $1: 11$ \\
\hline 2 & 4 & 17 & $8: 10$ & $1: 46$ \\
\hline 3 & 38 & 51 & $1: 11$ & $0: 24$ \\
\hline 4 & 4 & 22 & $8: 14$ & $2: 01$ \\
\hline
\end{tabular}

Tab. 1. Comparison of key indicators of production

\section{CONCLUSION}

Simulation model should help to assess the effects of the new technical and organizational structure of the welding lines for continuous production, hence the overall productivity lines.

Creating a simulation model by given the available information from the production system was very fast. High efficiency of this approach is demonstrated in the operational implementation of changes to the production system and the creation of alternative solution proposals.

Although the simulation model of the production system in the presented case does not excel particularly high complexity and scale, its benefits are obvious and clearly demonstrable, see Table 1. Objective problems, assessment of the new layout of the proposed deployment of welding workplaces have been met and due towide possibilities for further application of the simulation model the contractor has the interest in the digitalization of other parts of his production system.

\section{REFERENCES}

Bangsow, S. (2010). Manufacturing Simulation with Plant Simulation and SimTalk: Usage and Programming with Examples and Solutions, Springer-Verlag, ISBN 978-3642-05073-2, Berlin Heidelberg

Harrison, D.K., Petty, D.J. (2002): Systems for Planning \& Control in Manufacturing, MPG Books Ltd., pp. 165-172. ISBN 0-7506-49771, Bodmin, Cornwall

Košturiak, J., Frolík, Z. (2006). Lean and innovative business, Alfa Publishing, ISBN 80-86851-38-9, Praha

Mikoláš, Z. (2005): How to increase business competitiveness, Grada Publishing. ISBN 80-247-1277-6, Praha

Tayfur A. (1996): Performance Analysis of Manufacturing systems, Springer-Verlag, ISBN 0-387-94773-6

Warner, G. A. (2009). Discrete-Event Modeling and Simulation: A Practitioner's Approach, Taylor \& Francis Group, LLC. ISBN 978-1-4200-5336-4, USA 